\title{
PHOTOCROSSLINKING OF WATER-SOLUBLE POLYMERS BEARING A PENDANT CYCLOHEXENONE MOIETY
}

\author{
MASAHIRO TSUNOOKA, YOSHIHIDE AMEKAWA, and MINORU SASHIO \\ Department of Applied Chemistry, College of Engineering, \\ University of Osaka Prefecture \\ 1-1, Gakuen-cho, Sakai, Osaka 591 Japan
}

We have reported that the reaction of poly(vinyl alcoho1) (PVA) with methyl viny1 ketone under basic conditions gives water-soluble polymers which have a pendant $a, \beta$-unsaturated carbony1 group (a cyclohexenone moiety) [1] and their films become insoluble in water very effectively when irradiated with UV light [2]. It was deduced that the insolubilization was caused by the photodimerization of pendant $a, \beta$-unsaturated groups and that the aggeregation and segment motion of the pendant groups induced the highly-efficient photodimerization. The amount of $\alpha, \beta$-unsaturated carbony 1 groups in the polymers, however, was one-tenth of pendant saturated carbonyl groups and it was difficult to differentiate the aggregation and segment motion of $a, \beta$-unsaturated carbony 1 groups from those of saturated carbonyl groups. Thus, in order to get the information of photochemical behavior of pendant $a, \beta$-unsaturated carbony 1 groups, the PVA which has a small amount of a pendant $a, \beta$-unsaturated carbonyl group (a cyclohexenone moiety) only was required. In this article, we report the preparation of PVA which has only pendant $a, \beta$-unsaturated carbony1 groups (PCPVAR) and its photochemical behavior.

The route of polymer preparation was shown in Scheme $I$. The introduction of pendant $a, \beta$-unsaturated carbony 1 groups into PVA was carried out as follows: (1) the reaction of hydroxyl groups in (4) with (3) in the presence of DCC and (2) partial hydrolysis of (5) under basic conditions.

Figure 1 shows the IR specra of (4), (ㅁ), and (6)). Absorption bands at 3330,1715 , and $1655 \mathrm{~cm}^{-1}$ were assigned to hydroxy1, ester carbony1, and $a, \beta-$ unsaturated carbonyl groups, respectively. Since the absoption band at 


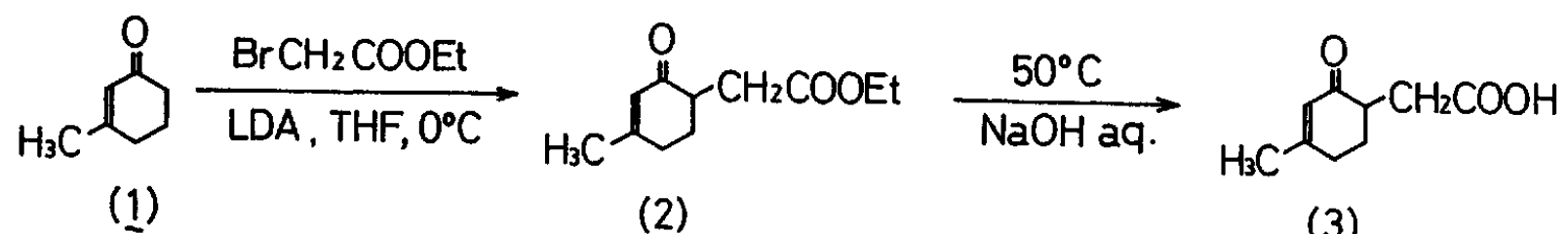

(1)

(2)

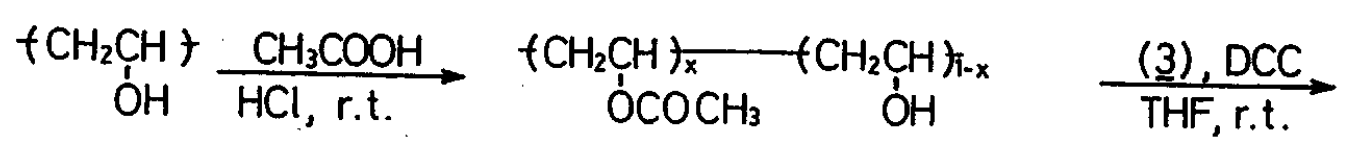

(4)

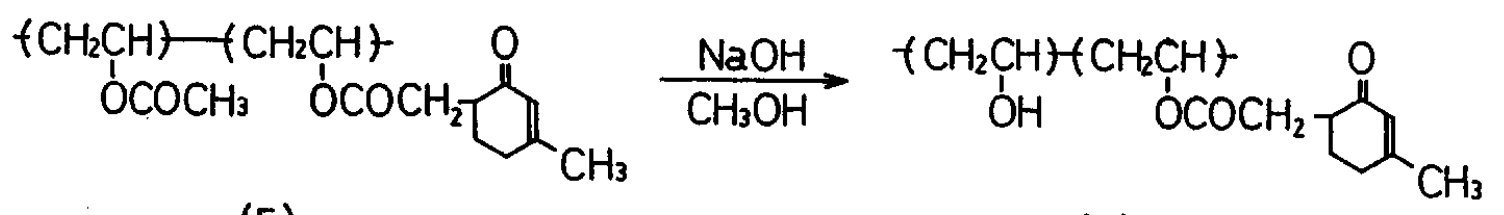

(5)

(6)

LDA: 1ithium diisopropylamide, DCC: dicyclohexy1 carbodiimide

Scheme I

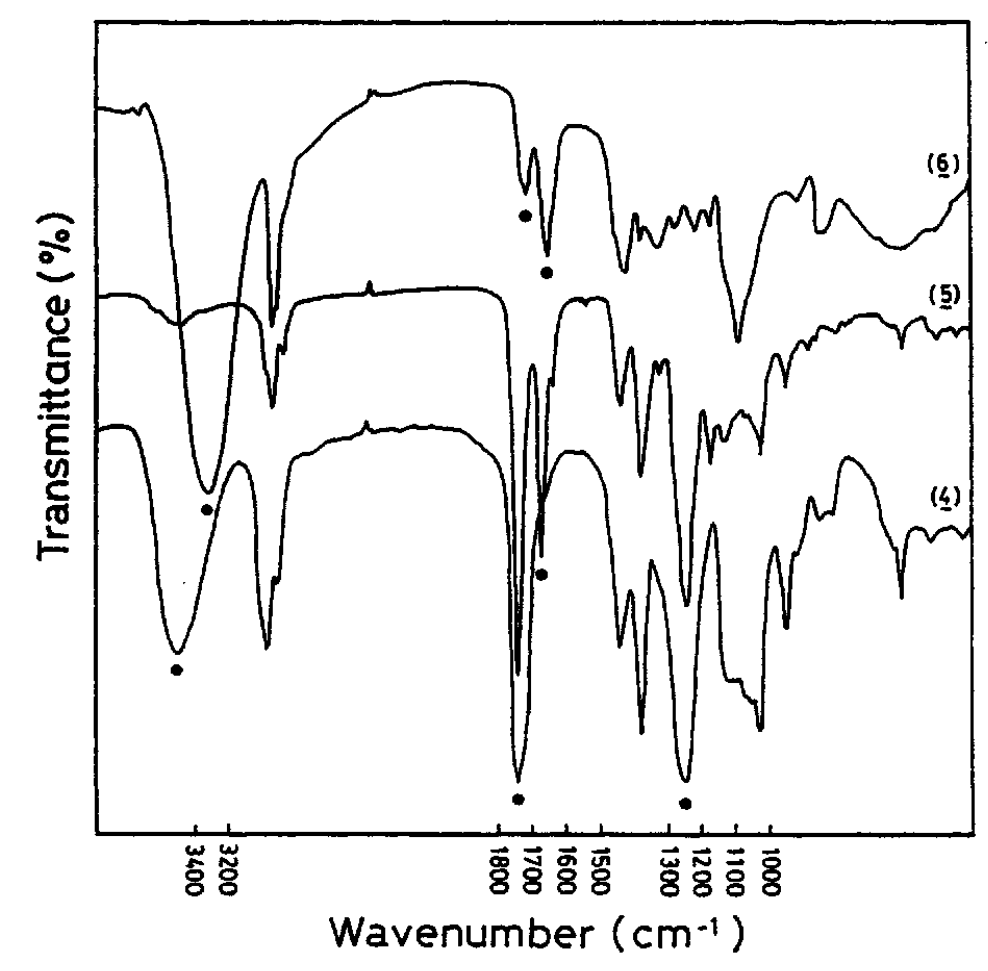

Figure 1. IR specra of polymers: (4), (ㅁ) , and (ㅁ) 


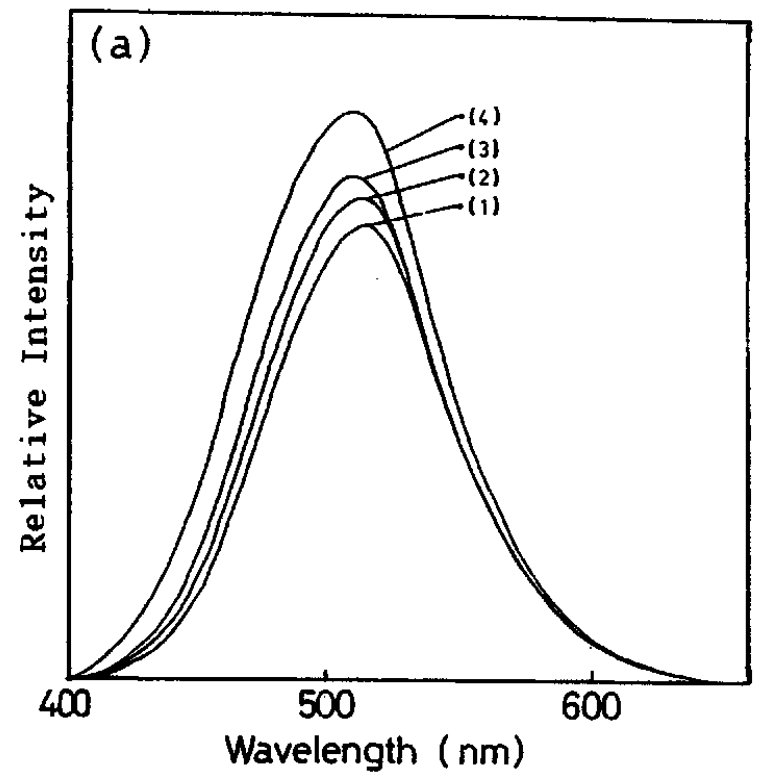

Figure 2. Emission spectra of aqueous solutions of ANS: (1)water, (2) PVA, (3) PCPVA-R2, and (4) PCPVA-R1. [polymer] $=1.0 \mathrm{~g} / 1$, [ANS] $=0.18 \mathrm{~g} / 1$, $\lambda_{e x}: 380 \mathrm{~nm}$ at $30 \mathrm{q}$

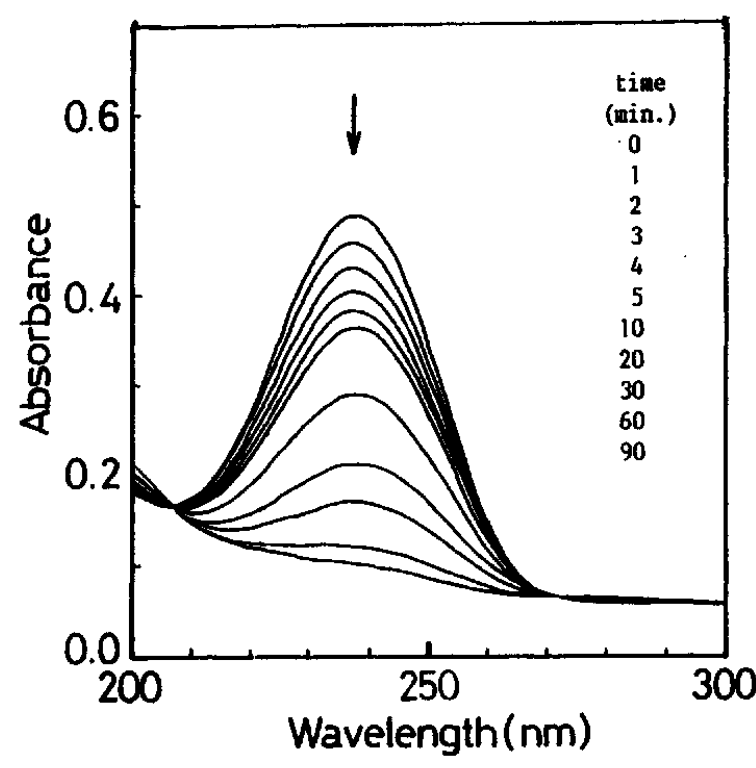

Figure 3. Changes in UV spectra of a PCPVA-R1 film irradiated at $254 \mathrm{~nm}$.

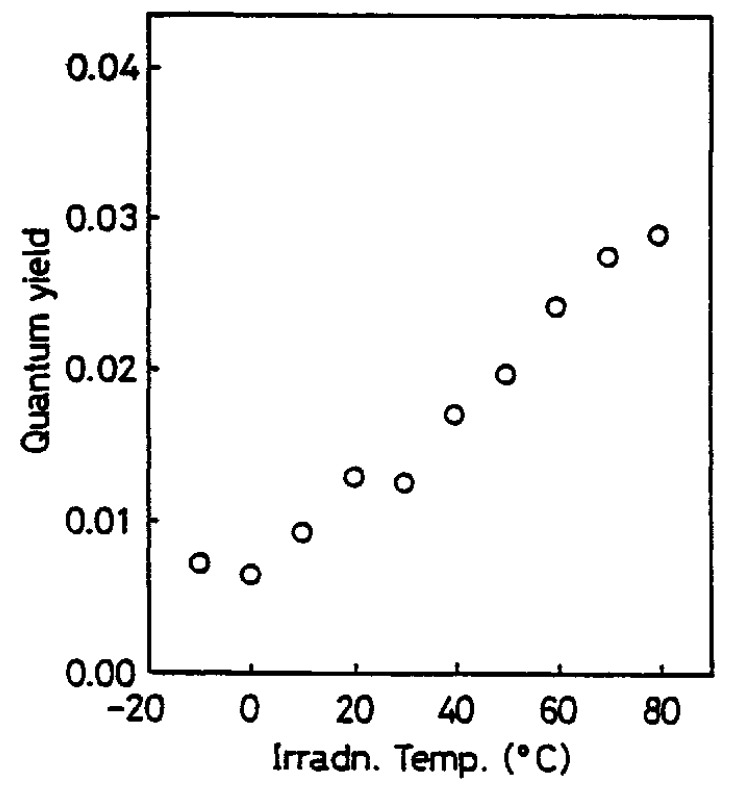

Figure 4. Relationship between irradiation temperatures and quantum yields of disappearance of pendant $\alpha, \beta$-unsaturated carbony 1 groups in PCPVA-R1. 
$1240 \mathrm{~cm}^{-1}$ assigned to acetoxy groups in (6) was very weak, it is deduced that a1most a11 of the acetoxy groups in (6) were removed and that a sma11 amout of pendant $\alpha, \beta$-unsaturated carbonyl groups remained in (6). Two kinds of PCPVARs (No 1 and No 2) were prepared and contents of $a, \beta$-unsaturated carbony 1 groups in them, which were determined from their UV specra, were 3.36 and 0.09 mo1\%, respectively.

Figure 2 shows the emission spectra of ammonium N-phenyl-1-aminonaphthalene- 8-sulfonate [ANS] solutions containing polymers. In Fig.2, emission intensities increased in the following order: PVA $\angle P C P V A-R 2<P C P V A-R 1$, which suggests that the introdution of $a, f$-unsaturated carbonyl groups in PVA increased the hydrophobic properties of polymers and that pendant $a, \beta$-unsaturated carbony1 groups aggregated with each other by hydrophobic interaction with increasing contents of $\alpha, \beta$-unsaturated carbony 1 groups.

Figure 3 shows UV spectral changes of a PCPVA-R1 film irradiated at $254 \mathrm{~nm}$. The absorbance around $237 \mathrm{~nm}$ decreased with irradiation time. The plots of 1/Abs. against irradiation time gave a linear relationship, suggesting that the photoreaction proceeds in the second order of the concentration of pendant $a, \beta$-unsaturated carbonyl groups. In the IR spectrum, the absorbance at $1656 \mathrm{~cm}^{-1}$ ( $a, \beta$-unsaturated carbonyl groups) decreased with UV irradiation, and the absorbance at $1714 \mathrm{~cm}^{-1}$ (saturated carbony1 groups) increased simu1taneous $1 y$. These results support that the pendant $a, \beta$-unsaturated carbony 1 groups disappeared by their photodimerization upon UV irradiation.

In order to estimate the effect of temperature on photoreactivities of pendant $a, \beta$-unsaturated carbony 1 groups, we measured quantum yie1ds of disappearance of $a, \beta$-unsaturated carbonyl groups (Fig.5). The quantum yields increased with irradiation temperatures. This result indicates that the segment motion of pendant $a, \beta$-unsaturated carbonyl groups in the polymer matrix a1so plays an important role in their photodimerization. The activation energy calculated from Fig.5 was $15.5 \mathrm{~kJ} / \mathrm{mol}$. Further details are under investigation.

\section{References}

1. M.Tsunooka, N.Nakajo, M.Tanaka, and N.Murata, Koubunshi Ronbun-shu, 23, 451 (1966)

2. M.Tsunooka and Y.Amekawa, Proc. RadTech Asia '91, 431 (1991) 